\title{
Tension and Flow: an Analysis on the Emotional Structure of The Peony Pavilion
}

\author{
Yanping Chen \\ Collage of Literature and Journalism \\ Sichuan University \\ Chengdu, China 610064
}

\begin{abstract}
Influenced by the conditions of developed commodities economy and Yang Ming philosophy of mind, there emerged a new wave of social thoughts focusing on secularism and affirming human desire in the middle and late Ming Dynasty. Tang Xianzu, who has fully absorbed the essence of this emerging social thought trend, has involved it into the legendary The Peony Pavilion in a creative way. This work, which affirms the desires of the secular people, has stroked the dominant social concept with the core of Cheng Zhu's Neo-Confucianism in a very clear-cut manner. In the works, this sharp contradiction is deeply expanded. The emotional tensions reflected in the development and evolution of it is in line with Raymond Williams' description of the "emotional structure" theory. Therefore, this paper uses Raymond Williams' emotional structure theory as a perspective to comb and analyze the emotional structure embodied in The Peony Pavilion.
\end{abstract}

Keywords-The Peony Pavilion; emotional structure; benevolence of living; true feelings

\section{INTRODUCTION}

Tang Xianzu's legendary "The Peony Pavilion" in the Wanli 26th year of Ming Dynasty (1598), with a strong sense of against Neo-Confucianism and feudal rituals, shows a strong characteristic of pursuing individual freedom, and represents the feelings of a group of people who were aware of it at that time to a large extent. Therefore, since the day when the book was circulated, a group of loyal readers, especially female readers have been gathered. The original words of Lin Yining, a female reader of the Qing Dynasty, in the Preface to the Returning Ghost: When the book was first published, scholars all bought it to put it on their desk. Tang Xianzu also wrote in his poem "Two Poems for the Women Who Crying by Lou River" that "why did she die for love? There must be something to be sad. It is only the literature in a period of time, but the people who like literature in the world are influenced." to sincerely respond to readers' concern and affection for the "The Peony Pavilion" in the book.

The reason why "The Peony Pavilion" can be so widely and lastingly circulated is because it not only has rich and meandering plots, elegant and mellow words, but also has deep rebellious thoughts, so the book can not only be used for pastimes, but also can give people a strong soul vibration and even resonance. Through this subtle influence, readers receive irreplaceable emotional education. This is an emerging emotional concept that is different from traditional feudal ethics and is based on the affirmation of lust. It was rejected and guarded by the feudal Guardian. In the 42nd chapter of "A Dream of Red Mansions", the secret warning of Xue Baochai's warning to Lin Daiyu was the evidence, and she used the admonitory words: "I'm most afraid of being changed by miscellaneous book". It also proves that the book "The Peony Pavilion" shaped the temperament of the girls in the Ming and Qing Dynasties.

The emotions are never merely related to individuals, but also closely related to the social culture style at that time. In other words, the seemingly very personal emotions are actually closely related to the infiltration of social culture. Social culture differs from time to time. Even the cultures in the same time, are not highly mixed and united in the types of emotions. There are dominant type, remnant type, and emerging type. Raymond William's structure of feeling theory carried out an in-depth discussion of this. Although Raymond Williams's definition of "emotional structure" has changed in different arguments at different times, the socalled emotional structure is "people's overall feeling for life" in general (1954, "Film Introduction".), "culture in a period of time" and "a type of social experience that is always in a dissolved state" (1961 "The Long Revolution"), as well as an "emerging cultural element that has not fixed in a pre-emergence state" (1977 Marxism and Literature).

In these definitions, it is particularly important to note that Raymond Williams used to place descriptive words such as "dissolved state" and "not yet fixed" before "social experience" and "cultural factors." These words contain the meaning of change and imply the intrinsic complexity of the sensory structure. That is to say, the sensory structure of an era is not indistinguishable like the iron plate, but may be the mixture of all social and cultural states in the past, present, and future stages.

"The Peony Pavilion" is a legendary book written in the middle and late Ming Dynasty. It is widely spread and is considered by the mainstream feudal class as a poisonous and herbaceous book type that should be banned since it can transform people's temperament. Because of the special environment and the sharp advance of the author, its emotions and thoughts conform to Raymond Williams' 
characteristic description of the "dissolved state" and "not yet fixed" of the emotional structure. Therefore, analyzing from the perspective of Raymond Williams' emotional structure theory enables us to better understand The Peony Pavilion as well as Tang Xianzu and the times trend in the time of Tang Xianzu.

\section{RESISTING THE REASON WITH EMOTION: DU LINIANG'S DREAM AND DEATH}

In the part of author's inscription of The Peony Pavilion, Tang Xianzu wrote: "I don't know why I love you but it becomes deeper when I realize it. It can make living person die and die person alive. If living people can't die for love, or the dead can't revive because of love, they don't have deep love." These words use the method of a combination of positive and negative expositions, and affirm the emotions that have the power to break through the bound of death and life in an absolutely decisive tone. However, this kind of power, placed in the real world where we live, will inevitably be ridiculous for people. In this regard, Tang Xianzu's response is: "it won't happen from the perspective of the reason, but how can we know if it won't happen from the perspective of emotion" [1]. That is to say, the things that can't be tolerant under the standard of the reason have much space to exist under the standard of emotion. Such an act of listing the things that can't exist from the perspective of "reason" and must exist from the perspective of "emotion" hint the clearest position of Tang Xianzu's resisting "reason" with "emotion".

The real expansion of the confrontation between emotion and reason is promoted by Du Liniang, the protagonist of "The Peony Pavilion". In other words, the author of the legendary, Tang Xianzu wrote the emotion with a pen and added the anti-reason spirit filling in his mind to the role of $\mathrm{Du}$ Liniang that he makes efforts to shape. Although Du Liniang is only a woman and she may appear weaker than men in rebellion, as the role who is most constrained and hindered by the creed of Cheng Zhu Neo-Confucianism "exterminating the desire and keeping the natural law", once she awakens, she can use her weakness to compel the instinct of life, and then bursts forth the most rebellious forces.

Of course, as weak illuminati, Du Liniang does not possess the power to destroy the feudal ethics order with the core of Cheng Zhu Neo-Confucianism. Therefore, there are only two paths before her: "changing her hobbies or destroying it and one must be chosen from the two. [2] $\mathrm{Du}$ Liniang, who naturally loves beauty, chose to abandon the reality to find love in dream and abandon life for ghosts. In her view, as long as "flowers and herbs are loved by humans, and life and death depend on people's wishes", then even becoming sick and dying for love and is also "distressed but no one would complain". [1] That is to say, for Du Liniang, to live in the world, the most important thing is to be able to release youth, publicize personality, love and hate as one wishes. If she can't do it, she would rather die.

The reason why Du Liniang had to make the difficult choice to compromise or die, on the one hand, it was because of the circumstances of the age in which she lived, and on the other hand, it is related her temperament. Mr. Cai Yuanpei once pointed out in the "History of Chinese Ethics": "Since the Song Dynasty, everything is according to the reason instead of emotion. It is believed that widows will lose their chastity if they remarry. It was said that the starvation is minor matter but losing chastity is severe. Therefore, women are immersed in poverty and can never get out!" In the late Ming dynasty of the feudal society, the ruling class attached more importance to feudal ethics and morality. Therefore "the feudal rites and chastity concept advocated by the confucianists" , "not only became a universal social moral identity, but also are translated into the main moral beliefs and behavioral standards in the hearts of a vast number of women."[3] Such attention and recognition are particularly prominent in the important part of the establishment and promotion of the ethical and moral aspects by the bureaucratic home. Women born and raised in such an environment are either domesticated into mothers and wives conforming to the three obedience and the four virtues, such as Du Liniang's mother Zhen who "only acted as a spinning brick" for the whole life and "know a little bit of courtesy" [4], or awakening but unwilling to change and can only compromise or die early in order to end the suffering in heart, such as the protagonist Yu Erniang in Tang Xianzu's "Two Women Weeping by the Min River". Besides, they may also struggle to rebel after awakening, which is an impossible task that transcends the times. Tang Xianzu had a clear understanding of this, so when setting up the scene for the plot, he did not design an activity space that allows talents and beauties live relatively freely like the authors of many previous Scholar-Beauty Romances. Instead, he dwells on the abstract and avoids real issues to put unfulfilled rebellion into imaginary dreams and death.

The different interpretation of A Fair Maiden is the trigger for Du Liniang's resistance. In the seventh section of "The Peony Pavilion", "Boudoir school", when pedant Chen Zuiliang is about to interpret the book based on annotations, $\mathrm{Du}$ Liniang rejected it skillfully: "Master, student can interpret the book according to annotations by myself. Please tell the general meaning of Book of Songs". Chen Zuiliang did in line with her words, and said: "Many elegant boudoirs ... don't envy, and then the concubine becomes virtuous ... ... which is decent and suitable for a family", but then he was interrupted by the sudden question "how many are the scriptures". [4]Du Liniang's boredom and rejection of traditional feudal morality can be seen here. Although she can also cope with it mildly, she can forget it immediately after that, so she can inquire that "where is the garden" and "is there any scenery" without hesitation after scolding the maidservant. She also has a keen sense of intuition, so she can make the sign of "people are not as good as birds" from the interpretation of A Fair Maiden, and then she have the feeling to visit gardens.

Ordinarily, even if they are strictly restrained in normal times, it is not unusual for them to visit their own back garden and it doesn't need to take pains. Du Liniang commanded Chun Xiang "to get the clothes and the mirror," and "spent half a day to make the flower decoration". She was dressed so beautiful that the maids close to here couldn't 
help to exclaim "Good Dress Today." [4] The so-called saying that a girl will doll herself up for people who love her means that girls know their beauty, and often show their beauty for the love in their hearts. However, if the girl in deep yard only makes needlework in spare time and study ethic, to who can she show the beauty? It is like "beautiful flowers" "are all paid to the old well". Therefore, she becomes sentimental, falls asleep, and has a relationship with the scholar whom she has never met before. This kind of behavior is amazing in a real situation, and it is also bold in a dream. This shows the braveness in Du Liniang's heart. However, even in dreams, it is impossible to escape the control of feudal ethics, because it will be awakened by her mother who abides by feudal ethics. Even if the dream with unclear object is "enveloped in the shadow of feudal rituals" [4], Du Liniang is not willing to give up. Instead, she seeks it again with love because this is where she can best stretch her nature and is the last light that can support her to endure the harsh ethics. However, the dream that have been made has no trace like the birds that have been hidden from the sky. Du Li Niang can only describe herself to death, and then she uses the ghost's "virtual feelings" to break the "rites" that the living people must follow." So far, she returns to make the decisive battle to resist reason with emotions.

According to the foregoing discussion, it can be seen that in a country where Cheng Zhu Neo-Confucianism is the official ideology, Du Liniang's every behavior is strictly regulated and controlled. Therefore, she can only transfer the mood of seeking for freedom to dreams and deaths. In other words, dreams and deaths became the space for Du Liniang's temperament to make struggle, which is a compelling choice. It can be seen the helplessness of the author Tang Xianzu as well as Tang Xianzu's accurate grasp of the real situation. However, although she fights against Neo-Confucianism only in the imaginary space of dreams and deaths, it did not reduce the intensity of the rebellion, because Du Liniang chose the method of resistance that affected Cheng Zhu's "exterminating the desire" kernel, namely the satisfaction of the desire and love. This can be proved in the tenth chapter of The Peony Pavilion "Waking from Dream". In the Chapter "Waking from Dream", Du Liniang feel sad for the spring when visiting the garden (actually feel sorry for herself). She became sleepy because of her sadness for the spring and fell asleep. After that, she had sexual relationship with an unnamed Xiucai whom she has never met before. After waking up in the dream, she feels unhappy and "only hope to return to the old dream". She even followed the dream to find the way by carrying out detailed memories about the desire and love such as "He softly touched me with tenderness". [1] From the unnamed characteristics of the Xiucai whom Du Liniang made love with and her memories of the details afterwards, it can be seen that what Du Liniang is not immersed in the love based on specific objects, but a kind of satisfaction of desire based on life instinct.

This point is essentially different from the love patterns written in the previous works of scholar and beauty romance, such as The West Chamber. Tang Xianzu is well aware of the denseness, complexity and intensity of oppression of the reality. Under such oppression, Du Liniang has no chance to meet a man she loves, and certainly there is no room for love. However, although the feudal ethical order with the core of Cheng Zhu Neo-Confucianism could spread a vast network that suffocates all external relationships, it cannot extinguish the flames of desire rooted in the depth of life instinct. With this kind of flame, there is an opportunity for life and death.

The emphasis on this life instinct (desire for love) is not the original creation of Tang Xianzu himself, but is jointly promoted by the economic and cultural thoughts of an era. In the middle and late Ming dynasty when Tang Xianzu lived, Cheng Zhu Neo-Confucianism "has lost the original meaning of saving souls, criticizing power, and building order" "after a long process of ideological institutionalization. It has become an empty moral code and pale dogma text", which calls for a lively thought that can renew this era. [5] The development of the commodity economy led to the development of an extensive market economy [6] and the emergence of early capitalism. It also enabled the public at that time to break away from the primitive farming-based life and be stimulated by the desire of industrial and commercial development, so it shows the sign of relaxation in the effort to restrain the desire. In response to this trend, Wang Yangming tried to bridge the reason and human desire under the Neo-Confucianism interpretation method by re-declaring the classics of Confucius and Mencius in order to settle the divided physically and mentally. Some descendant of Wangschool connects "the mortal with the saints, the daily life with the ideal realm, the secular realm with the soul body" and then "affirm the rationality of daily life and worldly lust". [5] Combining the convenient communication conditions brought about by the development of city commerce, transportation, and printing and papermaking technologies, these thoughts are deeply rooted in the hearts of the people, and they are transformed into a fierce rebel trend of thought that affects a group of radical people including Tang Xianzu and others who have idealistic color. And then use their creations to strengthen the power of rebellion. The appearance of "The Peony Pavilion" is a vivid interpretation and a vigorous launch of this rebellion trend.

\section{COMPROMISED RECONCILIATION}

Although Tang Xianzu actively response to the new trend of thought "affirming the rationality of daily life and sexual passion" that has gradually emerged and became popular among the ideological and civil sectors with creative methods and has showed clear rebel standpoint of resisting the reason with emotions, as a person who took part in an eight-part essay examination and then entered the official division, Tang Xianzu also had some habit of traditional Confucian scholar. In other words, the fierce collision between the dominant form (Cheng and Zhu NeoConfucianism) and the emerging style (the affirmation of the secular eroticism) that occurred in the social culture in the period of the middle and late Ming dynasty also took his heart as the battlefield and launched the confrontation between reason and emotion. This contradiction is not surprising, because no matter how one rebels, there is the past that can't be get rid of linked to its flesh and blood. In 
fact, Tang Xianzu's rebellion is not so much an initiative, but rather a conceptual change that forced by harsh reality.

However, after Tang Xianzu turned to the ideological trend of affirming "sexual passion", he still did not break away from the Confucian scholars' words and actions. This can be confirmed by his discussion of the connotation and function of "emotions." Tang Xianzu, who studied in the Taizhou School of Philosophy, absorbed the academic purpose of the "benevolence of living", advocated by his teacher Luo Rufang. This is a kind of academic purpose that is related to the "kindness principle of love and inferiority advocated by the Confucianists. It is easy to combine with the developed commodity economy and the increasingly strong material desires in late Ming Dynasty to constitute the academic purpose that individual passions and the country are simultaneously associated with each other. [7] Tang Xianzu constantly merges this academic purpose into his own personality traits in the enriching social experience and turns it into his own political and literary perspective. This category related to "emotions" with the connotation of "benevolence of living" is naturally not only limited to the sentiments of men and women, but also "a spirit of the universe" and "the vitality of nature" with the feature of encouraging the circle of life in the world. [7] Such a universal spirit that encourages the love of men and women is the essence of the world. The world is a sentient world and all living creatures are sentient beings. Of course, the world is not merely composed of emotions, but also includes both reason and power. Using his original text in the "Preface to Shen's Ge Shuo", it is "There are three factors needed to be noticed when doing things: reason, power, and emotion. These three factors are taken to manage the good or ill luck in the world and determine the success or failure of all things." However, that era lacks emotion most. There are only rituals and power flooded in society, making people unhurried, without freedom, and the whole society was lifeless, so he would cry out for emotion and expect the arrival of a sentimental world. [7]

It can thus be seen that what Tang Xianzu said was not intended to abolish the entire content of "rationalism," but to correct the improper use of reason (rites) in any area. In Tang Xianzu's view, the sentient world should be guided by a sentient approach in order to achieve the effect of "taking the human's emotion as joyful teaching" ("Record in Yihuang County Play God Qingyuan Shi temple"), namely reason and emotion accompany each other, with emotion assisting reason, rather than limiting reason with emotion. Here, we can feel the spirit of Tang Xianzu as a Confucian scholar who is impregnated in the tradition of Confucius and Mencius. The eighth chapter of "The Peony Pavilion" "Encouragement of Agriculture" is the vivid interpretation of the spirit bearing the burden of the world. In fact, the "Encouragement of Agriculture" is not indispensable in the overall repertoire of "The Peony Pavilion". Although it is true that it can show the richness of Du Bao's character, it is a bit of a sloppy nature for the plot and the center that the author wants to highlight. However, Tang Xianzu used the wording with light and cheerful color such as "the mountains are clear and the water is also clear, so people are walking in the shady mountain road" and "the officials are clean, so the villagers have nothing to go to the court" [1] to draw a picture of the ideal political picture of a clear mutual understanding between nature and humanities. In fact, this picture is Tang Xianzu's textual presentation of his own experience and is very much valued by him. He transferred the experience that he valued so much to Du Bao in the form of letters. It can be seen that Tang Xianzu is rich in the ambition of the traditional Confucian scholars who are upright for the people. However, Du Bao, who is entrusted the ideals of Tang Xianzu, has gradually fallen into the depths of the ethical order of the feudal dynasty and has become a paranoid people who only speaks of ethics and does not recognize his daughter due to the promotion of official position and urgency of national situation. Du Bao's evolution, or the complexity of $\mathrm{Du} \mathrm{Bao}$, is actually the difference in the emotional structure between Tang Xianzu and his contemporary gentry's class: Tang Xianzu and his fellows highlight emotion and resist reason, and others predominant ruling classes use reason to restrict emotion.

With this division, there is confrontation, although they also share a common Confucius and Mencius tradition. All confrontations will enter the face-to-face confrontation stage and will eventually evolve into a situation where one side defeats the other. Therefore, in the "The Peony Pavilion", Du Liniang, a valiant warrior for emotion created by Tang Xianzu, can rely on the virtual space of dreams and deaths to carry out rebellion, but the effect of rebellion must be verified through the actual confrontation. Then, there is the need for Du Liniang's revival from death. After her rebirth, Du Liniang was married to Liu Mengmei, but she was not recognized by her father Du Bao and her mother Zhen. In order to gain recognition, Du Liniang and Liu Mengmei had to go to Beijing to win the rationality and legitimacy for their marriage through the way that Liu Mengmei ranks the first in examination and emperor orders to reconcile. Although the love of Du Liniang and Liu Mengmei is complete in terms of its outcome, this kind of harmony and consummation is achieved through the involvement and even recognition of the process that attracts the talents and controls the people's heart, which was designed by the ruling class at that time. From this point of view, the complete ending of Du Liniang and Liu Mengmei is exactly a result of the weakening of the rebellious force that $\mathrm{Du}$ Liniang resists the reason with emotion crossing the line of life and death.

This process of breaking away from the mainstream ideology and finally being recognized by the mainstream ideology shows the contradictions of the author Tang Xianzu who has both traditional Confucian ambitions and emerging trends of thought. It also shows that despite the spread of the mind philosophy and the development of the commodity economy have indeed changed people's ideological concepts to a certain degree. That is, they focus on daily life and affirm lust, but this emerging social experience and cultural factors do not have enough power to destroy the existing dominant cultural ethics. In this way, the rebellion can only be turned into a bubble, or it can become a sad compromise that makes people sign, which is like a person who constantly resists, but in the end he has to become the type 
he hates. The confrontation between Du Liniang's lust and the reason is like Du Liniang who finally wakes up from her dream. She has the tenderness in the dream and misses the tenderness of her dream, but can only die of grief because she can't find the dream again.

\section{CONCLUSION}

The middle and late Ming Dynasty was a historical period in which many changes took place in the economy, technology, and concepts. In this era of change, on the one hand, Cheng Zhu Neo-Confucianism, as the dominant cultural form at the time, tended to be extreme in the control of people's minds and concepts, stifling people's basic desires for life; on the other hand, the development of the commodity economy stimulated people to break the limitation and accept lust. At least it is necessary to reconcile the overly-bloated "reason" with the "emotion" with connotation of "benevolence of living". This change was written into the legendary work "The Peony Pavilion" by Tang Xianzu. With the experience of Du Liniang's death due to the dream and her rebirth from death, he vividly and deeply embodied the "social experience in dissolution" (emotions structure). On the one hand, He resists the reason with emotion, and on the other hand, he gave up emotion to the reason. Finally, the happy ending of the two people suggests the compromise of "feeling" to "rationality", which is regrettable but is limited by the helplessness of the times.

\section{REFERENCES}

[1] Tang Xianzu. The Peony Pavilion, Beijing: People's Literature Publishing House, 2010. 汤显祖《牡丹亭》, 北京: 人民文学出版 社, 2010 年。

[2] Xu Shuofang. Biography of Tang Xianzu, Nanjing: Nanjing University Press, 1993. p.128. 徐朔方《汤显祖评传》, 南京: 南 京大学出版社, 1993 年.第 128 页。

[3] Wang Ruiying, "Confucian rituals and the marginalization of the status of women", "World and History", No. 10, 2009. 王瑞英《儒家 礼教与妇女地位的边缘化》, 载《历史纵横》2009 年第 10 期。

[4] Xu Shuofang. Biography of Tang Xianzu, Nanjing: Nanjing University Press, 1993. Page 11. 徐朔方《汤显祖评传》, 南京: 南京大学出版社, 1993 年.第 11 页。

[5] Ge Zhaoguang. "The History of Chinese Ideology, Volume II", Shanghai: Fudan University Press, 2000.12. p. 427. 葛兆光《中国思 想史・卷二》, 上海: 复旦大学出版社, 2000.12.第 427 页。

[6] Bu Zhengmin. "The Confusions of Pleasure: Business and Culture in the Ming Dynasty," Beijing: Life, Reading, and New Knowledge, Sanlian Bookstore, 2004. p. 228. 卜正民《纵乐的困惑: 明代的商 业与文化》, 北京: 生活 - 读书 - 新知三联书店, 2004 年.第 228 页。

[7] Zuo Dongling, Wang school and the Mentality of Scholars in the Middle and Late Ming Dynasty, Beijing: People's Literature Publishing House, 2000.4, p. 608. 左东岭《王学与中晚明士人心 态》，北京：人民文学出版社，2000.4 第 608 页。 